NOTICE: this is the author's version of a work that was accepted for publication in Applied Energy. Changes resulting from the publishing process, such as peer review, editing, corrections, structural formatting, and other quality control mechanisms may not be reflected in this document. Changes may have been made to this work since it was submitted for publication. A definitive version was subsequently published in Applied Energy, Vol. 88, No. 12 (2011). DOI: 10.1016/j.apenergy.2011.05.057 


\title{
Using Size Distribution Analysis to Forecast Natural Gas Resources in Asia Pacific
}

\author{
Roberto F. Aguilera ${ }^{a}$, Ronald D. Ripple ${ }^{\mathrm{b}}$
}

\begin{abstract}
Increasing energy consumption in Asia Pacific will largely be met by fossil fuels. Natural gas production in the region presently ranks behind that of oil and coal. However, the abundance of gas could lead to a significant gas market share increase in the energy mix. The purpose of this paper is to estimate the total endowment of conventional gas in Asia Pacific. This is carried out with a Variable Shape Distribution (VSD) model that forecasts volumes in provinces that have not been previously evaluated. The endowment is then distributed across countries to show where volumes are most likely to be found. A breakdown between offshore versus onshore resources is also estimated. The results of the analysis show there is a significant gas endowment. The estimated distribution across countries and onshore/offshore areas provides insight into the relative economics of gas production, as well as a basis for potential investment decisions. With appropriate energy policies, it may be possible to tap the vast gas potential in Asia Pacific. Considering gas may be the most abundant, inexpensive, and clean fossil fuel, the outcome would be increased energy security and a low carbon economy.
\end{abstract}

Keywords: Natural gas; Availability; Size Distribution; Supply

1. Introduction

Energy services are a fundamental human need and are thus indispensable for human well-being.

Significant challenges exist, ranging from energy security, to energy poverty, to environmental quality.

In Asia Pacific, energy demand is expected to grow dramatically as the region experiences sustained

\footnotetext{
${ }^{a}$ Corresponding Author. Centre for Research in Energy and Minerals Economics (CREME), Curtin Business School, Curtin University, GPO 1987, Perth, Australia, 6845, Email: roberto.aguilera@ curtin.edu.au, Phone: 618-9266-9137

${ }^{\mathrm{b}}$ CREME, Curtin Business School, Curtin University, GPO 1987, Perth, Australia, 6845, Email: r.ripple@ @urtin.edu.au, Phone: 618-9266-3935
} 
1 economic growth [1]. A fossil fuel future, at least over the next 30 to 50 years, is the most realistic

2 scenario. The mix of fossil fuel production over the long term remains uncertain. The issue is whether

3 the role of natural gas in the energy mix will become more important and whether there will be enough

4 gas in the region to satisfy growing demand.

Over the past decade there have been only a few assessments of global natural gas resources. In

6 general, these estimates point to steadily growing resources. Although assessments are mostly in

7 agreement regarding reserves, they tend to diverge for total resource endowments. The same holds true

8 for the Asia Pacific region.

Some resource assessments also include gas from unconventional sources, such as coalbed

methane, shale gas, tight gas sands and hydrate. The distinction between conventional and

11 unconventional sources is becoming increasingly unclear. In fact, gas from unconventional sources

12 gradually supplements conventional production, especially in the United States where unconventional

13 gas accounts for nearly half of its domestic supply. This could become a reality in Asia Pacific as well,

14 which is believed to hold vast unconventional gas potential. Future research will assess the availability

15 of unconventional gas as well as the economic and policy implications for the region. In this paper, the

16 focus is on conventional natural gas using a Variable Shape Distribution (VSD) model that estimates

17 endowment volumes in previously unassessed provinces. The VSD is a statistical method known as size

18 distribution analysis that has proved useful for many decades as a simple and effective complement to

19 more complex and time-consuming geological methods. When various assessment methodologies

20 converge in their results, a higher degree of confidence in those results is provided.

21 Notwithstanding the strong possibilities of a natural gas and perhaps an eventual hydrogen

22 economy in Asia Pacific, there is concern among some energy analysts about a potential gas shortage in

23 the coming years. This would probably force the region to resort to an even more intensive use of coal. 
1 Furthermore, dramatic increases in energy prices would lead to devastating macroeconomic effects that

2 would undermine economic and environmental conditions.

Eventually, there will be a maximum peak in natural gas production. The question is when will it occur, and will it happen because of depletion or because of substitution to other energy sources, perhaps unconventional or non-fossil. According to pessimistic sources, the peak for natural gas is estimated to occur only a couple of decades after that of oil. An important issue in the debate is whether society will experience a smooth or difficult transition. cost. This includes not only production costs, but also externalities such as environmental and social costs. Over time, technological change will be important since it will presumably reduce all of these

11 costs. Although the past is not always an indication of the future, experience suggests that viable energy

12 alternatives, such as conventional and unconventional natural gas, could make the transition much 13 smoother than expected.

Furthermore, recent work $[2,3]$ suggests that there is enough conventional and unconventional gas, available at economic production costs, for society to substitute alternative sources before depletion becomes a problem. However, to avoid an abrupt, depletion driven peak in natural gas production and

17 the associated consequences, adequate investment in alternative sources must take place on a timely 18 basis. Nevertheless, we must not ignore investment opportunities to enhance and extend our access to 19 natural gas. The ability of technological advancement to offset the cost-increasing effects of depletion 20 will be fundamental.

21 Given the sheer size of the potential natural gas demand in Asia Pacific, temporary shortages 22 might still occur due to problems that include lack of infrastructure, lack of spare capacity, political 
1 instability, natural disasters, strikes, shortage of qualified workers, shortage of refining capacity,

2 commodity manipulation by speculators, and the power of national gas companies.

\section{Previously Evaluated Natural Gas Volumes in Asia Pacific}

conventional natural gas endowment volumes, which are equal to known (cumulative production plus

7 remaining reserves) plus undiscovered volumes (see Figure 1), for 77 Asia Pacific provinces. ${ }^{1}$ The study

8 relies on various geological techniques combined with probability assessments to account for the

9 uncertainty. They publicize the mean values, which are the volumes used in this paper.

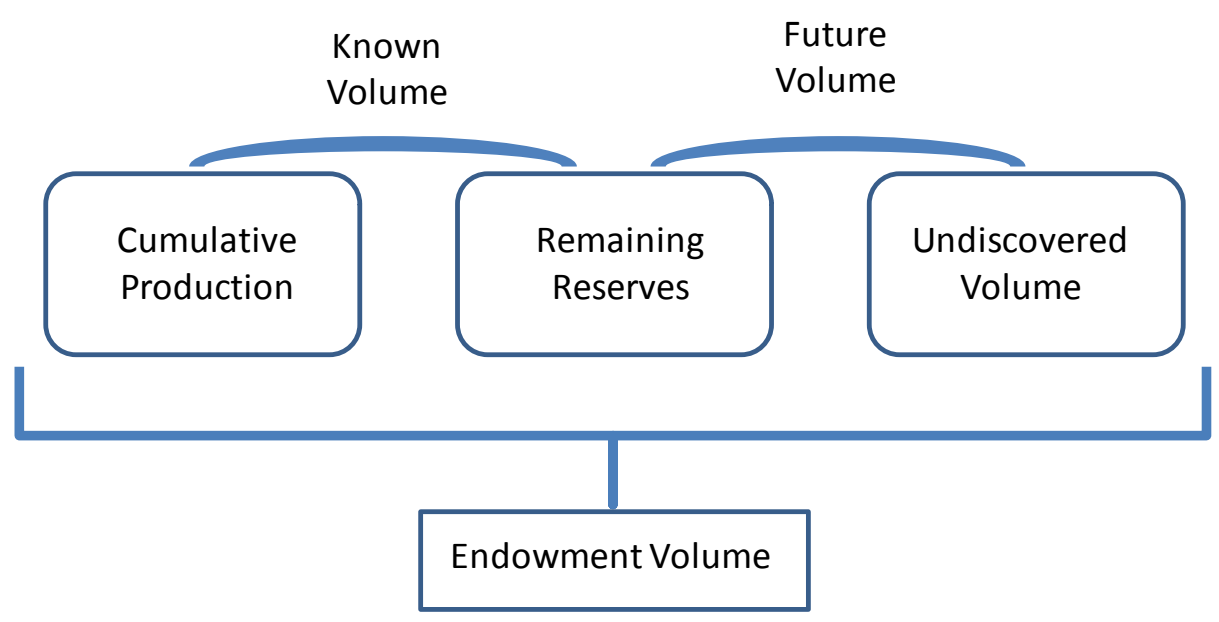

13 Fig. 1. The relationship between cumulative production, remaining reserves and undiscovered volumes.

\footnotetext{
${ }^{1}$ The USGS (2000) study [4] assesses 11 provinces in 'South Asia' and 66 provinces in their version of 'Asia Pacific'. In our study, the Asia Pacific region is equivalent to the combined USGS versions of both 'Asia Pacific' and 'South Asia'. Thus, our definition of Asia Pacific contains 77 provinces that were assessed by the USGS.

${ }^{2}$ USGS (2000) [4] recognizes totals of 29 provinces in 'South Asia' and 261 provinces in 'Asia Pacific'. Thus, there are 290 provinces in our definition of Asia Pacific.
} 
1 within the adopted 30-year time horizon. As stated by the USGS, "assessed areas were those judged to

2 be significant on a world scale in terms of known petroleum volumes, geologic potential for new

3 petroleum discoveries, and political or societal importance." ${ }^{3}$ Furthermore, many of the unassessed

4 provinces are in remote areas where gas may exist but due to location and other factors are likely to be

5 high-cost and so presumed by the USGS to be of little commercial interest over its 30-year timeframe.

Figure 2 is an Asia Pacific map that shows the region divided into geologic provinces. Those

7 provinces assessed in [4] are highlighted with horizontal stripes. In this paper, we estimate the

8 endowment volumes for the unassessed provinces using a previously defined size distribution model,

9 called the Variable Shape Distribution (VSD) model [5]. Other models commonly used to forecast gas

10 supply are life cycle models (e.g. Hubbert's logistic curves), rate of effort models, geologic-volumetric

11 models, subjective probability models, discovery process models and econometric models. With regard

12 to size distribution analysis, Adelman et al. [6] state "the concept of deposit size distribution is an

13 essential component of models of petroleum supply designed to reflect industry behavior in a logical

14 way" (1983, p. 90).

\footnotetext{
3 In this case, the term 'petroleum' includes natural gas. This is because the USGS defines conventional petroleum as the sum of natural gas, natural gas liquids, and oil with more than 15 degrees API.
} 


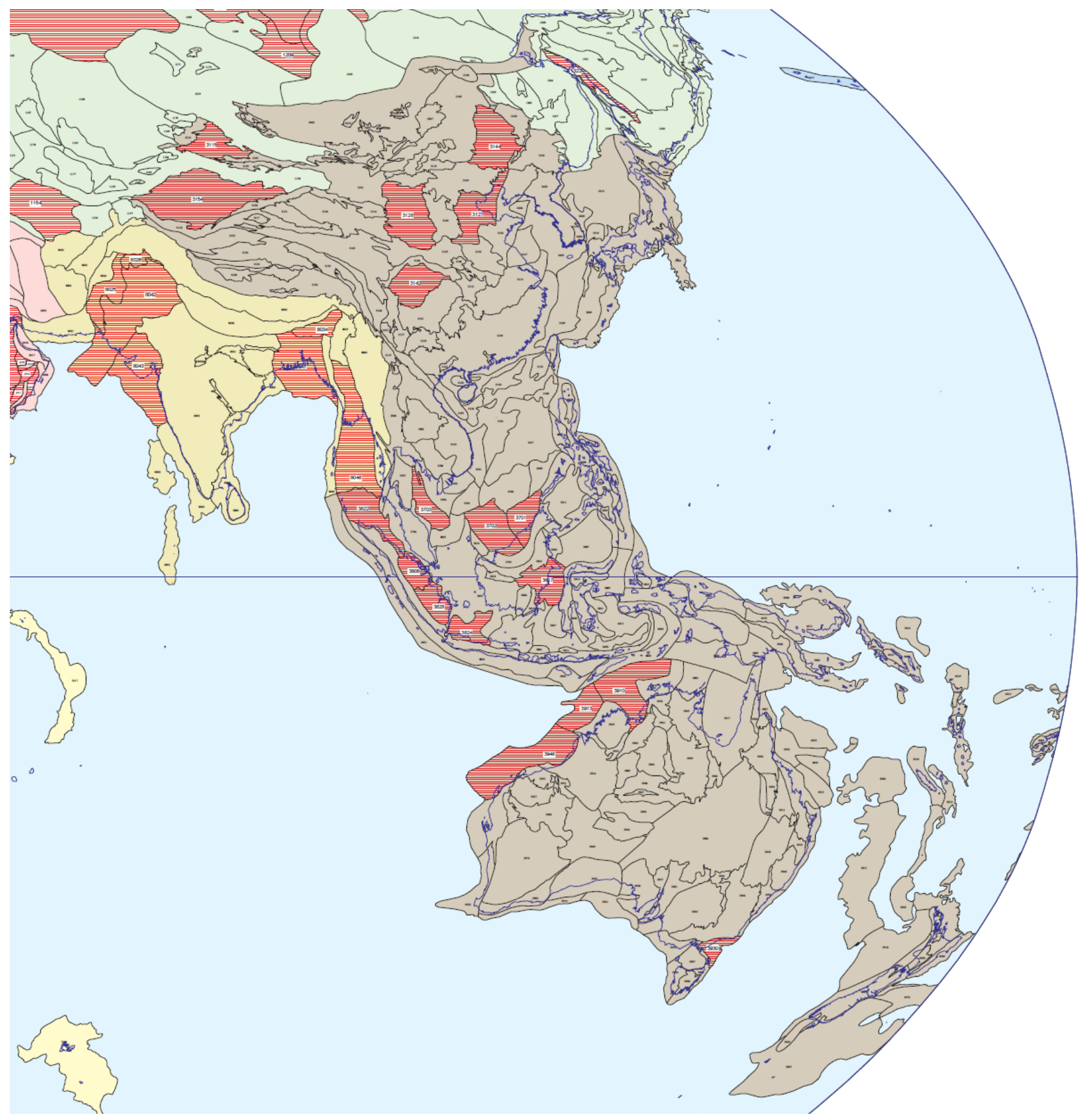

Fig. 2. Asia Pacific map divided into geologic provinces [4]. 


\section{The Variable Shape Distribution (VSD) Model}

Traditionally, all the methods used to forecast oil and natural gas volumes have been "based on

an assumed form of the size-frequency distribution of the natural population of oil and gas

accumulations" [7]. The lognormal and Pareto (fractal) distributions are common size distribution models used to estimate petroleum volumes of unassessed areas. These types of statistical distributions are believed to be representative of many natural and social occurrences (e.g. resource distribution in nature; income distribution across population).

Some researchers believe that the distribution of nature's petroleum resources follow lognormal distributions [8]. However, other researchers claim that the lognormal distribution provides overly pessimistic results [9]. They observe that, with additional exploration, there is an on-going discovery process that can better be modeled with a Pareto distribution.

Over the past five decades, "scientists have engaged in honest debate about the form of the distribution. In the USGS, thinking has evolved from regarding the entire natural population as lognormal to recognizing that a fractal or power-law distribution better predicts the increasing numbers of small accumulations" [7]. More recently, it has generally been acknowledged that the Pareto distribution tends to overestimate petroleum resources, while the lognormal distribution tends to underestimate them.

The VSD is unique in that we start by observing the curvature (on a log-log plot) given by the size and number of provinces from [4]. We then develop the VSD model which allows the data to determine the specified relationship between the size and number of provinces. Next, the model is extended out of sample such that (1) the cumulative number of provinces is the sum of the number of assessed and unassessed provinces, (2) the largest and smallest provinces are constant and known. 


\subsection{Description of the VSD Methodology}

The VSD method starts by ranking the assessed Asia Pacific provinces from [4] in decreasing

3 order by endowment volume. When the data is plotted on log-log coordinates, the vertical axis shows

4 the rank of a province according to its volume, while the horizontal axis shows the volume of the

5 province. Assuming most of the larger provinces have already been assessed (e.g. Northwest Shelf,

6 Kutei Basin, Greater Sarawak Basin, Malay Basin, Ganges-Brahmaputra Delta, Tarim Basin, and

7 others), the VSD calculates volumes for provinces that have not been assessed in the past. Thus, the

8 slope of the approximate straight line (i.e. the Pareto Distribution - see Figure 3) given by the assessed,

9 larger provinces remains constant as we include unassessed provinces in the ranking.

As with all size distribution models, the original sample used to estimate the parameters contains

11 most of the largest data in terms of endowment volumes. This allows us to estimate the slope and

12 intercepts of the straight line given by the largest data. These parameters remain constant during the

13 volumetric forecasting of the previously unassessed provinces. Many of these unassessed provinces are

14 in areas where gas may exist but due to location and other factors are likely to be higher cost resources.

\subsection{Parameter Estimation and Validation for Asia Pacific}

The gas endowment volumes for the 77 Asia Pacific provinces assessed by [4], shown in the

fourth column of Table 1, have been used to estimate the parameters of the VSD model using non-linear regression.

\section{Table 1}

Gas endowment volumes for 77 Asia Pacific provinces assessed by [4]. 


\begin{tabular}{|c|c|c|c|c|c|c|c|c|}
\hline \multicolumn{2}{|l|}{$\begin{array}{l}\mathrm{R}^{2} \text { coefficient of } \\
\text { determination }=\end{array}$} & \multirow[b]{3}{*}{$\begin{array}{c}\text { Cumulative \# of } \\
\text { Provinces } \\
\mathrm{N}_{\mathrm{t}}\end{array}$} & & $\begin{array}{l}a_{p}= \\
r_{m}=\end{array}$ & $\begin{array}{c}0.697 \\
7.1429 \mathrm{E}-06\end{array}$ & & $\begin{array}{l}\mathrm{N}_{\mathrm{x}}= \\
\mathrm{N}_{\mathrm{m}}=\end{array}$ & $\begin{array}{c}77 \\
1\end{array}$ \\
\hline \multirow[b]{2}{*}{ Province Code } & \multirow[b]{2}{*}{ Province Name } & & & $\begin{array}{c}V_{\mathrm{s}}= \\
\Psi= \\
\text { severity }=\end{array}$ & $\begin{array}{c}3707 \\
0.02532303 \\
1.1456242\end{array}$ & & $\begin{array}{c}\mathrm{V}_{\mathrm{x}}= \\
\mathrm{V}_{\mathrm{m}}= \\
\mathrm{a}_{\mathrm{m}}= \\
\left(\mathrm{r}_{\mathrm{m}}\right)^{\mathrm{am}}=\end{array}$ & $\begin{array}{l}1,540 \\
0.011 \\
0.367 \\
0.013\end{array}$ \\
\hline & & & $\begin{array}{c}\text { Gas } \\
\text { Endowment } \\
\text { (TCFG) }\end{array}$ & $r_{v}$ & $r_{t}$ & $a_{t}$ & function & $\begin{array}{c}\hat{V}_{i} \\
\text { (TCFG) }\end{array}$ \\
\hline & TOTAL & & 1099.632 & & & & & 1101.219 \\
\hline 3948 & Northwest Shelf & 1 & 120.956 & 0.98142 & 0.98143 & 0.00000 & 2.85484E-01 & 126.074 \\
\hline 3817 & Kutei Basin & 2 & 110.230 & 0.35621 & 0.35622 & 0.67152 & $1.03030 \mathrm{E}-01$ & 110.476 \\
\hline 3702 & Greater Sarawak Basin & 3 & 101.411 & 0.19530 & 0.19531 & 0.67268 & 5.37363E-02 & 98.026 \\
\hline 3703 & Malay Basin & 4 & 75.614 & 0.12676 & 0.12676 & 0.67119 & 3.32823E-02 & 85.583 \\
\hline 8047 & Ganges-Brahmaputra Delta & 5 & 67.380 & 0.09023 & 0.09023 & 0.66911 & $2.27426 \mathrm{E}-02$ & 74.099 \\
\hline 3154 & Tarim Basin & 6 & 65.719 & 0.06808 & 0.06809 & 0.66683 & 1.65576E-02 & 64.041 \\
\hline 3701 & Baram Delta/Brunei-Sabah Basin & 7 & 59.426 & 0.05347 & 0.05348 & 0.66449 & 1.25995E-02 & 55.463 \\
\hline 3822 & North Sumatra Basin & 8 & 40.682 & 0.04325 & 0.04326 & 0.66211 & $9.90449 \mathrm{E}-03$ & 48.228 \\
\hline 3913 & Browse Basin & 9 & 38.053 & 0.03577 & 0.03577 & 0.65972 & $7.98220 \mathrm{E}-03$ & 42.144 \\
\hline 8043 & Bombay & 10 & 37.137 & 0.03010 & 0.03011 & 0.65733 & $6.56055 \mathrm{E}-03$ & 37.020 \\
\hline 3910 & Bonaparte Gulf Basin & 11 & 36.796 & 0.02569 & 0.02570 & 0.65495 & $5.47830 \mathrm{E}-03$ & 32.688 \\
\hline 8042 & Indus & 12 & 35.560 & 0.02219 & 0.02219 & 0.65257 & $4.63468 \mathrm{E}-03$ & 29.006 \\
\hline 8048 & Irrawaddy & 13 & 30.530 & 0.01935 & 0.01935 & 0.65019 & 3.96399E-03 & 25.858 \\
\hline 3828 & South Sumatra Basin & 14 & 28.455 & 0.01701 & 0.01701 & 0.64781 & $3.42182 \mathrm{E}-03$ & 23.151 \\
\hline 8025 & Sulaiman-Kirthar & 15 & 28.376 & 0.01505 & 0.01506 & 0.64544 & 2.97725E-03 & 20.809 \\
\hline 3127 & Bohaiwan Basin & 16 & 24.186 & 0.01341 & 0.01341 & 0.64306 & $2.60818 \mathrm{E}-03$ & 18.771 \\
\hline 3142 & Sichuan Basin & 17 & 22.837 & 0.01200 & 0.01201 & 0.64068 & 2.29847E-03 & 16.989 \\
\hline 3824 & Northwest Java Basin & 18 & 15.508 & 0.01079 & 0.01080 & 0.63830 & $2.03610 \mathrm{E}-03$ & 15.423 \\
\hline 3930 & Gippsland Basin & 19 & 15.433 & 0.00975 & 0.00975 & 0.63591 & $1.81194 \mathrm{E}-03$ & 14.039 \\
\hline 3966 & New Guinea Foreland Basin-Fold & 20 & 11.000 & 0.00883 & 0.00884 & 0.63352 & $1.61900 \mathrm{E}-03$ & 12.812 \\
\hline 3805 & Bintuni/Sulawati Province & 21 & 9.500 & 0.00803 & 0.00803 & 0.63111 & $1.45181 \mathrm{E}-03$ & 11.718 \\
\hline 3507 & Thai Basin & 22 & 8.900 & 0.00732 & 0.00732 & 0.62870 & $1.30604 \mathrm{E}-03$ & 10.740 \\
\hline 3924 & Eromanga Basin & 23 & 8.500 & 0.00669 & 0.00669 & 0.62628 & $1.17825 \mathrm{E}-03$ & 9.861 \\
\hline 3159 & Yingehai Basin & 24 & 8.400 & 0.00612 & 0.00613 & 0.62384 & $1.06567 \mathrm{E}-03$ & 9.070 \\
\hline 3808 & Central Sumatra Basin & 25 & 7.944 & 0.00562 & 0.00563 & 0.62139 & $9.66024 \mathrm{E}-04$ & 8.355 \\
\hline 8034 & Assam & 26 & 7.712 & 0.00517 & 0.00517 & 0.61892 & $8.77470 \mathrm{E}-04$ & 7.707 \\
\hline 3809 & East Java Basin & 27 & 7.600 & 0.00476 & 0.00476 & 0.61644 & $7.98468 \mathrm{E}-04$ & 7.118 \\
\hline 3144 & Songliao Basin & 28 & 7.449 & 0.00439 & 0.00439 & 0.61393 & 7.27742E-04 & 6.582 \\
\hline 3031 & Taranaki Basin & 29 & 7.200 & 0.00405 & 0.00406 & 0.61141 & $6.64220 \mathrm{E}-04$ & 6.091 \\
\hline 3505 & Saigon Basin & 30 & 6.000 & 0.00374 & 0.00375 & 0.60887 & $6.06998 \mathrm{E}-04$ & 5.642 \\
\hline 3825 & Penyu/West Natuna Basin & 31 & 5.700 & 0.00346 & 0.00347 & 0.60630 & $5.55309 \mathrm{E}-04$ & 5.231 \\
\hline 3128 & Ordos Basin & 32 & 5.630 & 0.00321 & 0.00321 & 0.60370 & $5.08500 \mathrm{E}-04$ & 4.852 \\
\hline 3605 & Palawan Shelf & 33 & 5.600 & 0.00297 & 0.00298 & 0.60108 & $4.66011 \mathrm{E}-04$ & 4.503 \\
\hline 3115 & Junggar Basin & 34 & 3.879 & 0.00275 & 0.00276 & 0.59844 & $4.27358 \mathrm{E}-04$ & 4.181 \\
\hline 3606 & Pamusian Tarakan Basin & 35 & 3.600 & 0.00255 & 0.00256 & 0.59576 & $3.92125 \mathrm{E}-04$ & 3.884 \\
\hline 8026 & Kohat-Potwar & 36 & 3.245 & 0.00237 & 0.00238 & 0.59305 & 3.59949E-04 & 3.608 \\
\hline 3308 & Niigata Basin & 37 & 2.200 & 0.00220 & 0.00220 & 0.59030 & $3.30514 \mathrm{E}-04$ & 3.353 \\
\hline 3969 & Papuan Basin-Shelf Platform & 38 & 2.200 & 0.00204 & 0.00205 & 0.58752 & 3.03544E-04 & 3.116 \\
\hline 3151 & Taiwan Thrust and Fold Belt & 39 & 2.000 & 0.00189 & 0.00190 & 0.58471 & $2.78797 \mathrm{E}-04$ & 2.896 \\
\hline 3304 & Japan Volcanic Arc/Accreted Terr & 40 & 1.600 & 0.00176 & 0.00176 & 0.58185 & 2.56057E-04 & 2.691 \\
\hline 3181 & South China Continental Shelf SIc & 41 & 1.600 & 0.00163 & 0.00164 & 0.57895 & $2.35138 \mathrm{E}-04$ & 2.500 \\
\hline 3109 & East China Sea Basin & 42 & 1.400 & 0.00151 & 0.00152 & 0.57600 & $2.15870 \mathrm{E}-04$ & 2.322 \\
\hline 8045 & Krishna-Godavari & 43 & 1.400 & 0.00140 & 0.00141 & 0.57300 & $1.98106 \mathrm{E}-04$ & 2.155 \\
\hline 3958 & Surat Basin & 44 & 1.400 & 0.00130 & 0.00131 & 0.56996 & $1.81713 \mathrm{E}-04$ & 2.000 \\
\hline 3503 & Mekong/Cuulong/Vung Tau Basin & 45 & 1.300 & 0.00120 & 0.00121 & 0.56686 & 1.66573E-04 & 1.855 \\
\hline 3306 & Kanto Basin & 46 & 1.300 & 0.00112 & 0.00112 & 0.56370 & $1.52580 \mathrm{E}-04$ & 1.719 \\
\hline 3903 & Amadeus Basin & 47 & 1.200 & 0.00103 & 0.00104 & 0.56048 & $1.39638 \mathrm{E}-04$ & 1.592 \\
\hline 3950 & Otway Basin & 48 & 1.200 & 0.00095 & 0.00096 & 0.55720 & $1.27663 \mathrm{E}-04$ & 1.473 \\
\hline 3131 & Qaidam Basin & 49 & 0.800 & 0.00088 & 0.00089 & 0.55384 & 1.16577E-04 & 1.361 \\
\hline 3952 & Perth Basin & 50 & 0.700 & 0.00081 & 0.00082 & 0.55041 & $1.06310 \mathrm{E}-04$ & 1.256 \\
\hline 3502 & Khorat Platform & 51 & 0.700 & 0.00075 & 0.00075 & 0.54690 & $9.68009 \mathrm{E}-05$ & 1.158 \\
\hline 3806 & Bone Basin & 52 & 0.600 & 0.00069 & 0.00069 & 0.54331 & $8.79915 \mathrm{E}-05$ & 1.066 \\
\hline 3833 & Sumatra/Java Magmatic Arc & 53 & 0.500 & 0.00063 & 0.00064 & 0.53962 & $7.98304 \mathrm{E}-05$ & 0.979 \\
\hline 3153 & Taixinan Basin & 54 & 0.500 & 0.00058 & 0.00058 & 0.53584 & 7.22707E-05 & 0.898 \\
\hline 3611 & Sulu Sea Basin & 55 & 0.400 & 0.00053 & 0.00053 & 0.53195 & $6.52696 \mathrm{E}-05$ & 0.822 \\
\hline 3832 & Sumatra/Java Fore-Arc Basins & 56 & 0.400 & 0.00048 & 0.00049 & 0.52794 & 5.87882E-05 & 0.750 \\
\hline 3316 & Tsushima Basin & 57 & 0.400 & 0.00044 & 0.00044 & 0.52381 & $5.27911 \mathrm{E}-05$ & 0.683 \\
\hline 8044 & Cauvery & 58 & 0.400 & 0.00040 & 0.00040 & 0.51954 & 4.72458E-05 & 0.620 \\
\hline 3130 & Pearl River Mouth Basin & 59 & 0.300 & 0.00036 & 0.00036 & 0.51512 & $4.21226 \mathrm{E}-05$ & 0.561 \\
\hline 3147 & Subei Yellow Sea Basin & 60 & 0.300 & 0.00032 & 0.00033 & 0.51054 & 3.73947E-05 & 0.506 \\
\hline 3508 & Thailand Mesozoic Basin Belt & 61 & 0.300 & 0.00029 & 0.00030 & 0.50578 & $3.30371 \mathrm{E}-05$ & 0.454 \\
\hline 3907 & Bass Basin & 62 & 0.300 & 0.00026 & 0.00026 & 0.50082 & $2.90272 \mathrm{E}-05$ & 0.406 \\
\hline 3303 & Ishikari Hidaka Basin & 63 & 0.300 & 0.00023 & 0.00023 & 0.49564 & $2.53444 \mathrm{E}-05$ & 0.360 \\
\hline 8023 & Central Afghanistan & 64 & 0.271 & 0.00020 & 0.00021 & 0.49021 & $2.19698 \mathrm{E}-05$ & 0.318 \\
\hline 3804 & Barito Basin & 65 & 0.200 & 0.00017 & 0.00018 & 0.48450 & $1.88862 \mathrm{E}-05$ & 0.279 \\
\hline 3146 & South China Fold Belt & 66 & 0.200 & 0.00015 & 0.00016 & 0.47847 & $1.60778 \mathrm{E}-05$ & 0.242 \\
\hline 3305 & Joban Basin & 67 & 0.200 & 0.00013 & 0.00014 & 0.47207 & $1.35306 \mathrm{E}-05$ & 0.208 \\
\hline 3916 & Carnarvon Basin & 68 & 0.102 & 0.00011 & 0.00012 & 0.46524 & 1.12317E-05 & 0.177 \\
\hline 3103 & Beibuwan Basin & 69 & 0.100 & 0.00009 & 0.00010 & 0.45791 & $9.16993 \mathrm{E}-06$ & 0.148 \\
\hline 3156 & Turpan Basin & 70 & 0.100 & 0.00007 & 0.00008 & 0.44999 & 7.33525E-06 & 0.122 \\
\hline 3829 & Sulawesi Accretionary Prism & 71 & 0.100 & 0.00006 & 0.00006 & 0.44133 & $5.71923 \mathrm{E}-06$ & 0.098 \\
\hline 3160 & Yinshan Da and Xao Hingganling & 72 & 0.100 & 0.00004 & 0.00005 & 0.43179 & 4.31507E-06 & 0.077 \\
\hline 3609 & Reed Bank Basin & 73 & 0.100 & 0.00003 & 0.00004 & 0.42112 & 3.11789E-06 & 0.058 \\
\hline 3810 & East Natuna Basin & 74 & 0.100 & 0.00002 & 0.00003 & 0.40903 & 2.12535E-06 & 0.041 \\
\hline 3823 & Northern Irian Jaya Waropen Basi & 75 & 0.100 & 0.00001 & 0.00002 & 0.39516 & $1.33904 \mathrm{E}-06$ & 0.028 \\
\hline 3113 & Jiangnan South Jiangsu Fold Belt & 76 & 0.100 & 0.00000 & 0.00001 & 0.37954 & 7.68603E-07 & 0.017 \\
\hline 8035 & North Burma & 77 & 0.011 & 0.00000 & 0.00001 & 0.36658 & 4.64894E-07 & 0.011 \\
\hline
\end{tabular}


Figure 3 shows this data on a log-log plot of the cumulative number (rank) of provinces versus

3 the size of the provinces. These data points are plotted with the third and fourth columns from Table 1

4 and are represented by solid diamonds. Note that the data shows leftward curvature as the volumes

5 become smaller.

6

7

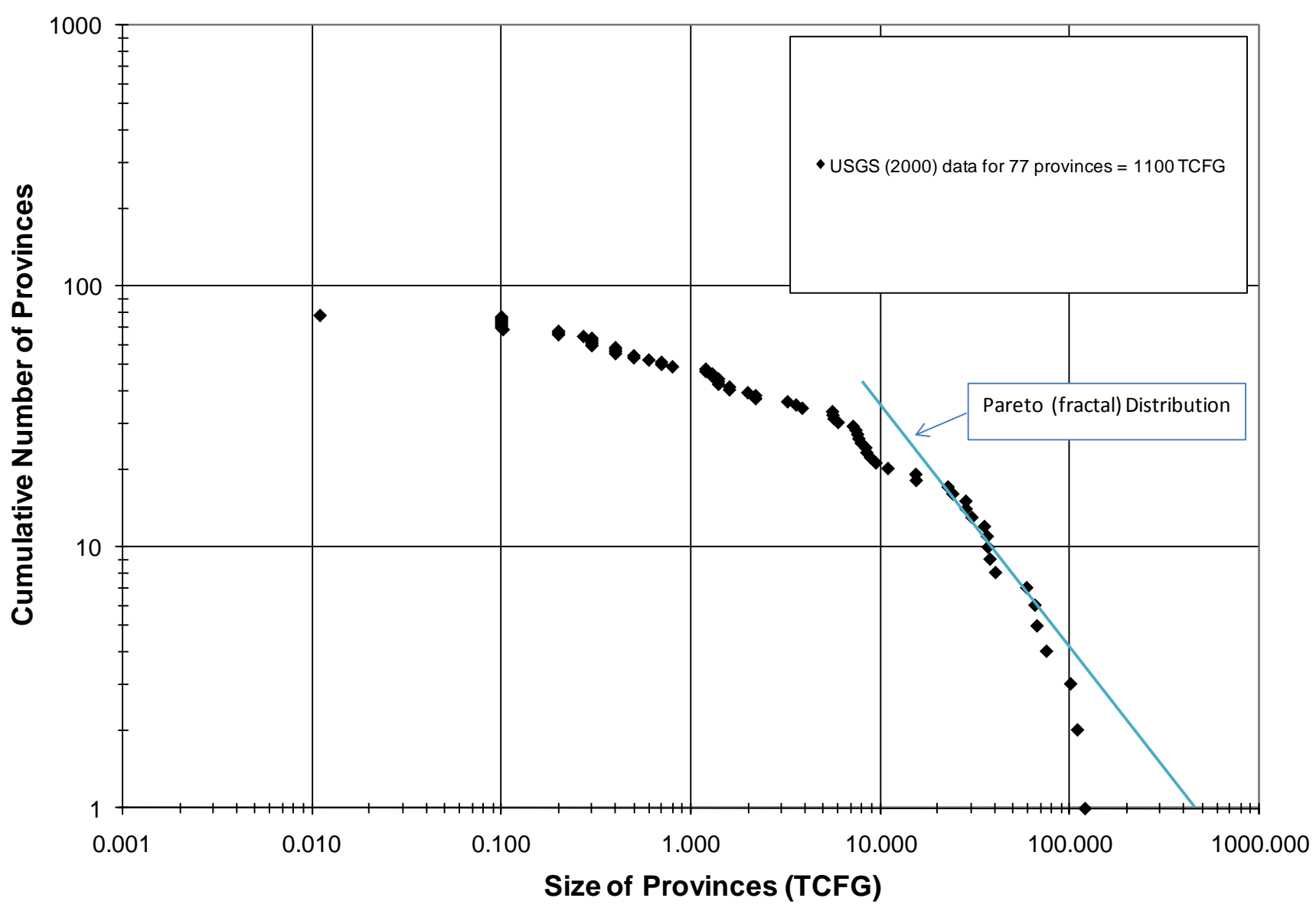

8

The next step is to use the VSD model to provide the best possible fit of the USGS (2000) data in Figure 3. In Equation 1, we present the VSD model as a non-linear least squares (NLS) model. In 
1 particular, the problem is to minimize the sum of the squared differences between the observed and

2 predicted sizes of the provinces: ${ }^{4}$

$$
\min _{\left\{V_{x}, a_{p}, V_{s}, \psi, S\right\}} \sum_{i=1}^{n}\left(V_{i}-\hat{V}_{i}\right)^{2}
$$

4 Subject to:

5

6

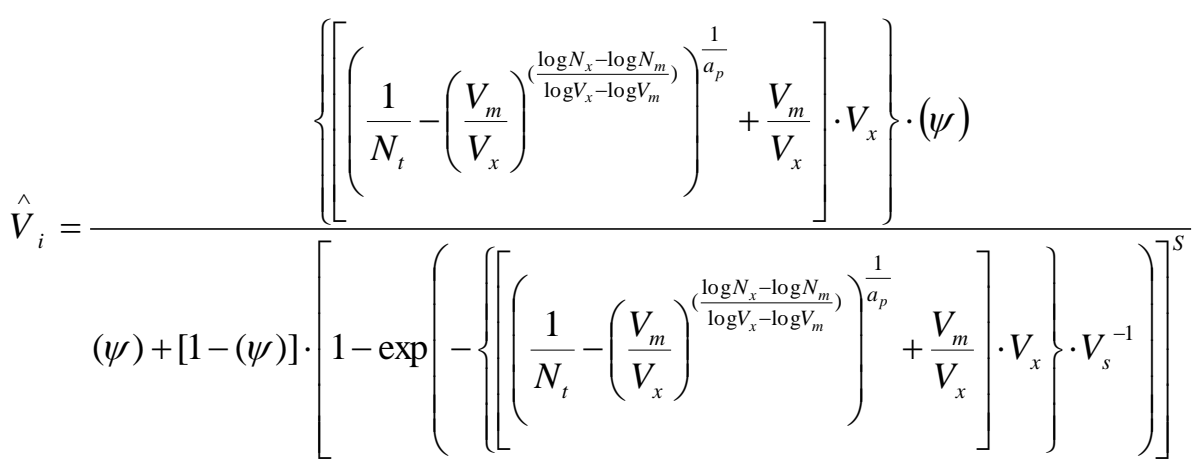

7 where:

$8 a_{p}$-slope of straight line approximated from USGS sample points with larger province volumes (same

9 as slope of Pareto distribution).

$10 N_{m}$ - minimum number of USGS provinces $(=1)$.

$11 N_{t}$ - cumulative number of provinces.

$12 N_{x}$ - maximum number of provinces.

$13 S$ - severity exponent that controls the steepness of the slope of the estimated VSD curve where it

14 separates from the Pareto straight line (on the right tail of the distribution, near the largest volumes).

$15 V_{m}$ - minimum USGS province volume (trillion cubic feet of gas, TCFG).

$16 V_{s}$ - approximate volume (TCFG) at which the USGS data begins to deviate from the Pareto straight line

17 (on the right tail of the distribution, near the largest volumes).

\footnotetext{
${ }^{4}$ Appendix A provides the mathematical development of Equations 1 and 2, and explains the nomenclature in detail. Schematics (Figures A.1 and A.2) illustrate some of the terms.
} 
$1 \quad V_{i}$ - observed volume of a province (TCFG).

$2 \quad \hat{V}_{i}$ - estimated volume of a province (TCFG).

$3 V_{x}$ - maximum volume (TCFG) given by the Pareto straight line (at $N_{m}=1$ ).

$4 \psi$ - separation ratio that controls the amount of separation between the Pareto straight line and the

5 estimated VSD curve (on the right tail of the distribution, near the largest volumes).

As seen in Equation 1, there are five parameters being estimated in the VSD equation $-V_{x}, a_{p}, V_{s}$,

$7 \psi$, and $\mathrm{S}$ - that cause the equation to best fit the volumes from [4] (i.e. to minimize the residual sum of

8 squares). The parameters are estimated based on visual inspection of the curves, comparison of actual

9 and estimated volumes, and inspection of the coefficient of determination $\left(\mathrm{R}^{2}\right)$. The VSD model is run

10 on the 77 Asia Pacific provinces for which gas endowment data from [4] exists. Table 2 shows estimates

11 of the five parameters that give the best fit.

12

\section{Table 2}

14 Parameters used for calculating assessed and unassessed natural gas in Asia Pacific. Parameters are 15 defined under Equations 1 and 2.

\begin{tabular}{|c|c|}
\hline Parameter & Gas, Asia Pacific \\
\hline $\begin{array}{c}V_{x} \text { - Maximum volume given by Pareto straight } \\
\text { line at } N_{m} \text { equal to } 1\end{array}$ & 1,540 TCFG \\
\hline$a_{p}$ - Pareto shape exponent & 0.697 \\
\hline$V_{s}$ - Volume of separation & 3,707 TCFG \\
\hline$\psi$ - Separation ratio & 0.025 \\
\hline$S$ - Severity exponent & 1.146 \\
\hline
\end{tabular}

17 


\subsection{VSD Validation}

Figure 4 is the same as Figure 3, but now shows a continuous solid line, which is the estimated

3 curve generated by the VSD model, using the above parameters.

4 5

6

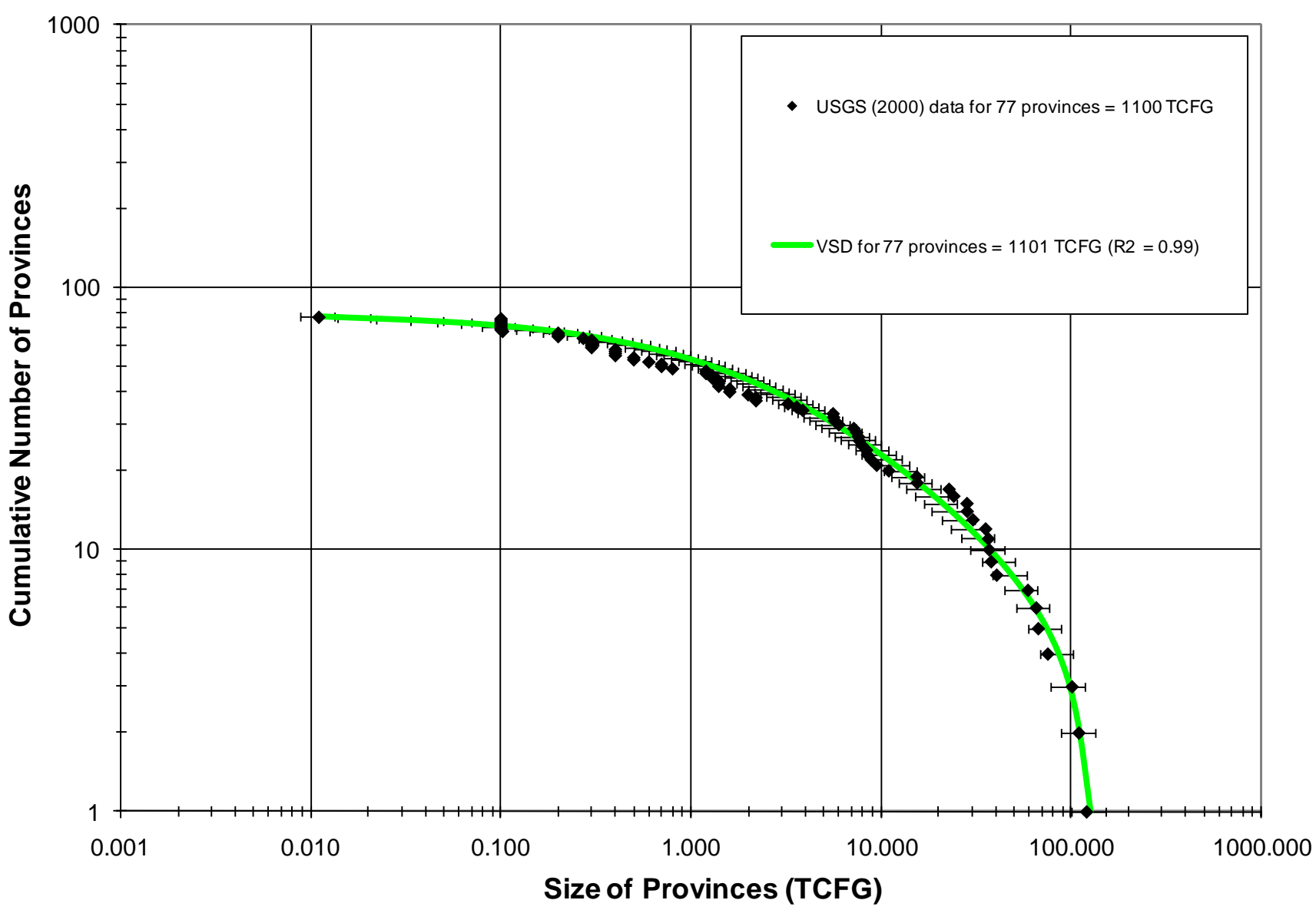

Fig. 4. VSD estimate for 77 Asia Pacific provinces. USGS (2000) data shows endowment volumes for 77 Asia Pacific provinces.

Visual inspection of the [4] data points and the estimated VSD curve shows a good fit, even for the largest provinces that do not lie on the Pareto straight line. In addition, the VSD calculated gas endowment volume of 1,101 TCFG, shown at the top of the last column $\left(\hat{V}_{i}\right)$ in Table 1 , compares well with the 1,100 TCFG published in [4]. This is supported mathematically by an $\mathrm{R}^{2}$ coefficient of 
1 determination equal to 0.99 . The good fit provides an initial validation of the VSD model. Estimated

2 volumes $\left(\hat{V}_{i}\right)$ generated by the VSD model for each province (presented in the last column of Table 1)

3 compare favorably with the actual USGS estimates (shown in the fourth column of Table 1).

4 17

\subsection{Accounting for Uncertainty}

Probability distributions are used in [4] to address the uncertainty associated with estimating gas volumes. Fractiles (F95, F50, F5, and the mean) are shown graphically in their study for undiscovered gas. The value of F50, for instance, would imply that there is a 50\% chance of the existence of at least the volume estimated. Inevitably, the uncertainties present in [4] extend to the VSD model.

The predictive power of the VSD model has been validated by a good fit of the size distribution of previously assessed Asia Pacific provinces. The fit is supported by a high coefficient of determination $\left(\mathrm{R}^{2}\right.$ of 0.99$)$ and an estimated VSD volume that is very similar to the one published by the USGS.

However, a comparison of the VSD curves with the USGS data points shows there are some differences at certain levels. The differences are accounted for in Figure 4 by plotting $20 \%$ horizontal error bars. As can be seen, in almost all cases the $20 \%$ error bars exceed the difference between the USGS and VSD calculated endowments. Asia Pacific provinces. The USGS has indicated that the region can be divided into 290 provinces, of which they have presented volumes for 77 . Table 3 provides a list of the previously assessed and unassessed provinces in the region.

\subsection{Application of VSD to Unassessed Provinces}

The VSD model may now be used to forecast gas endowment volumes in previously unassessed 
$1 \quad$ Table 3

2 Assessed and Previously Unassessed Provinces in the Asia Pacific region. 


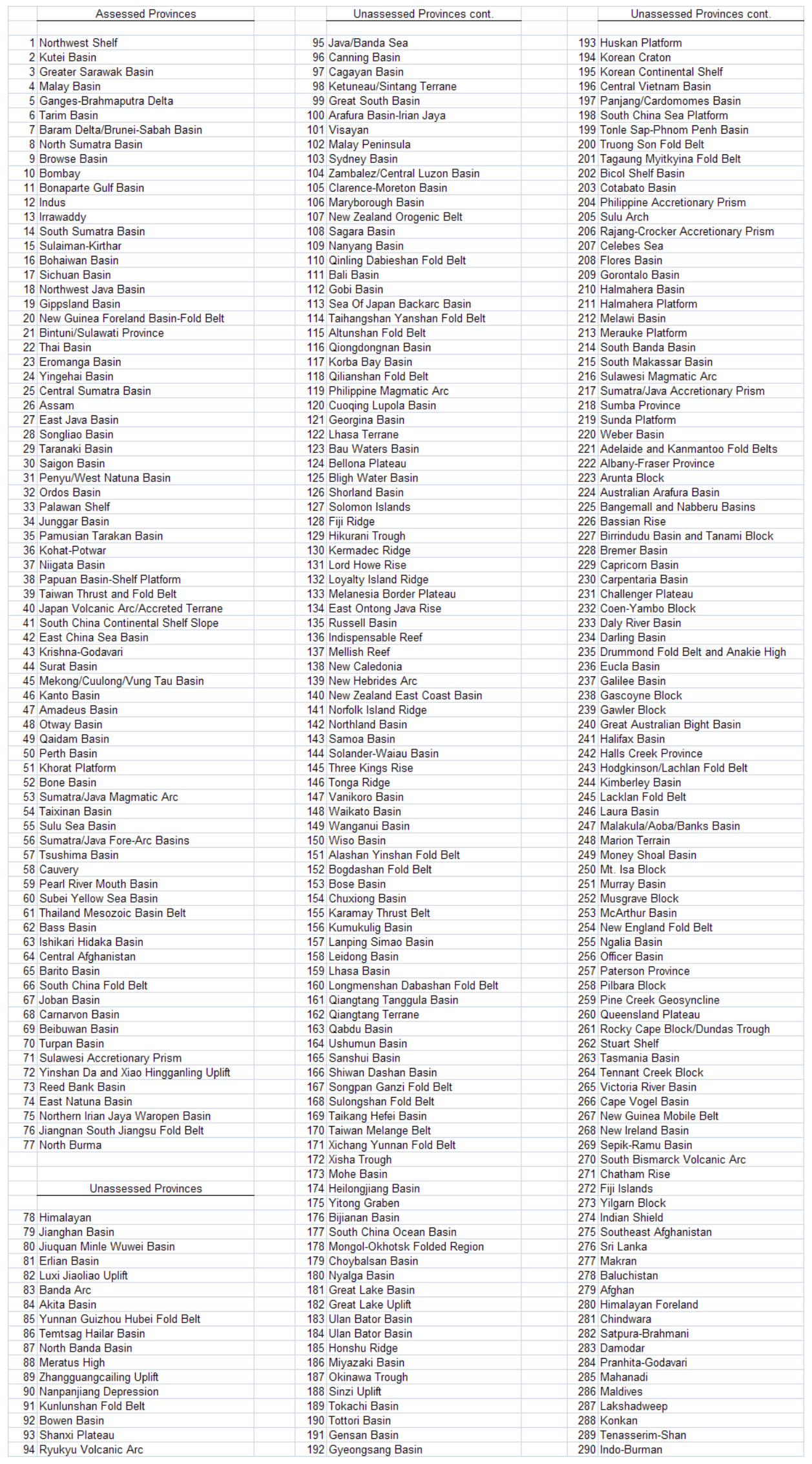


The estimated VSD curve for all 290 provinces is shown in Figure 5. The gas endowment

2 volume is calculated to be 1,437 TCFG. The same control parameters as before have been used to

3 generate the curve and volumetric estimates. The only change is the number of provinces being

4 evaluated, $N_{x}$, equal to 290 . The estimate of 1,437 TCFG cannot be compared with any volumes

5 estimated by the USGS or other organizations, since all 290 provinces have not been previously

6 assessed. However, the validations discussed earlier provide some confidence that the estimate is

7 reasonable. Although the VSD assumes most of the large provinces have already been discovered and

8 presented by [4], it is possible that some of the unassessed provinces will also be among the largest.

9

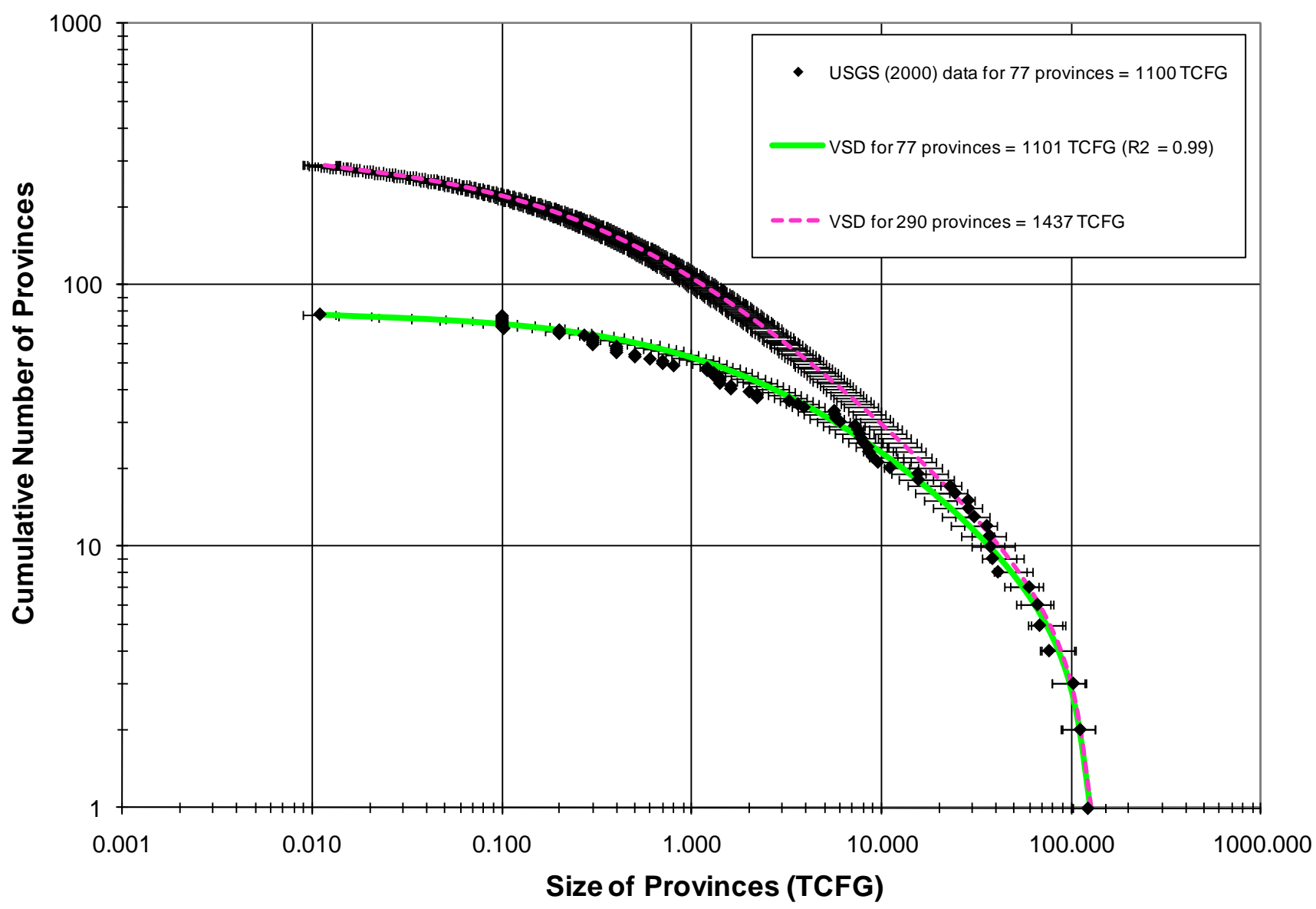

10

11

12

13

Fig. 5. VSD estimate for 290 Asia Pacific provinces (including previously unassessed provinces). 
While the VSD model provides endowment volumes for all 290 provinces, it does not indicate

2 which volumes correspond to which areas. To give an idea of where the natural gas may be located, we

3 have allocated the volumes among Asia Pacific countries on the basis of a country's share of

4 undiscovered volumes in USGS-assessed portions of the country. In other words, the distribution of the

5 total gas endowment among Asia Pacific countries will be the same as the distribution of undiscovered

6 volumes estimated by [4] in assessed portions of those countries. This approach assumes that countries

7 with high amounts of undiscovered volumes in previously assessed provinces will have unassessed

8 provinces with a generally proportional amount of gas. Using the chosen method, the largest gas

9 endowment volumes are allocated to Australia, Indonesia, and China, which together account for over

$1060 \%$ of the total (see Table 4 ).

11 Table 4

12 Allocation by Country of Asia Pacific Gas Endowment Volumes.

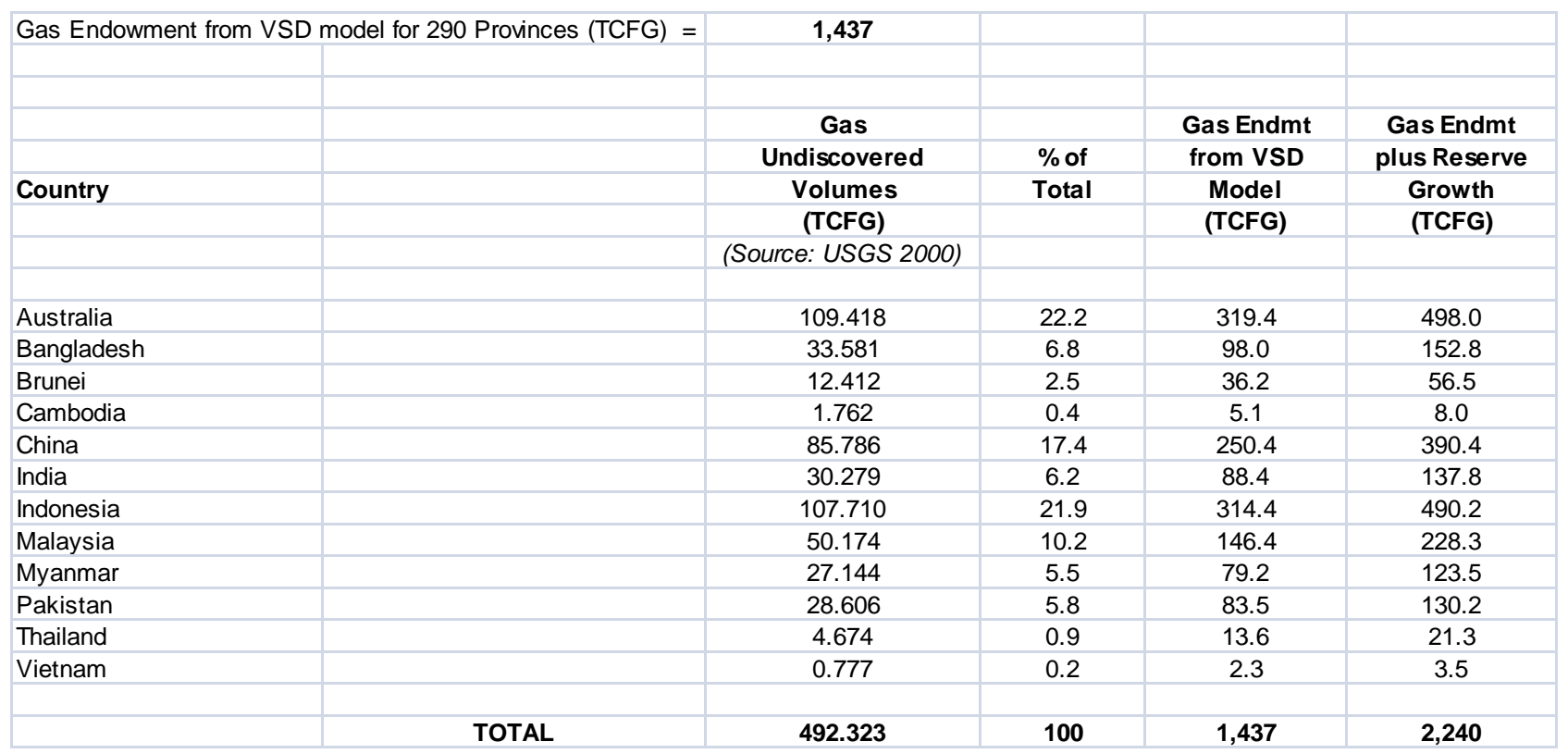

In addition to allocating results of the VSD model by country, we have also estimated the 
1 of Table 5 show this allocation of undiscovered volumes in Asia Pacific countries. The proportions are

2 given as percentages in columns 4 and 5. We have distributed the gas endowment total from all 290

3 provinces based on the onshore/offshore proportions estimated by [4] for each country. The results,

4 shown in columns 6 and 7, indicate that over $60 \%$ of the Asia Pacific natural gas endowment is located

5 in offshore areas. In Australia, approximately $97 \%$ of the endowment is located offshore. By contrast,

6 about $96 \%$ of the endowment in China is located onshore. Columns 8 and 9 include reserve growth,

7 which is explained in the following sections.

9 Table 5

10 Onshore versus Offshore Allocation of Asia Pacific Gas Endowment Volumes.

\begin{tabular}{|c|c|c|c|c|c|c|c|c|}
\hline 1 & 2 & 3 & 4 & 5 & 6 & 7 & 8 & 9 \\
\hline & & & & & Onshore Gas & Offshore Gas & Onshore Gas & Offshore Gas \\
\hline & Undiscovered & Undiscovered & & & Endmt from & Endmt from & Endmt plus & Endmt plus \\
\hline \multirow[t]{3}{*}{ Country } & Onshore & Offshore & Proportion & Proportion & VSD Model & VSD Model & Reserve Growth & Reserve Growth \\
\hline & Gas (TCFG) & Gas (TCFG) & Onshore (\%) & Offshore (\%) & (TCFG) & (TCFG) & (TCFG) & (TCFG) \\
\hline & (Source: USGS 2000) & (Source: USGS 2000) & & & & & & \\
\hline Australia & 3.419 & 105.999 & 3.12 & 96.88 & 9.979 & 309.392 & 15.6 & 482.4 \\
\hline Bangladesh & 15.445 & 18.136 & 45.99 & 54.01 & 45.081 & 52.936 & 70.3 & 82.5 \\
\hline Brunei & 0.439 & 11.973 & 3.54 & 96.46 & 1.281 & 34.947 & 2.0 & 54.5 \\
\hline Cambodia & 0 & 1.762 & 0.00 & 100.00 & 0.000 & 5.143 & 0.0 & 8.0 \\
\hline China & 82.143 & 3.643 & 95.75 & 4.25 & 239.761 & 10.633 & 373.8 & 16.6 \\
\hline India & 13.063 & 17.216 & 43.14 & 56.86 & 38.129 & 50.250 & 59.5 & 78.4 \\
\hline Indonesia & 43.419 & 64.291 & 40.31 & 59.69 & 126.732 & 187.654 & 197.6 & 292.6 \\
\hline Malaysia & 0.439 & 49.735 & 0.87 & 99.13 & 1.281 & 145.168 & 2.0 & 226.3 \\
\hline Myanmar & 9.335 & 17.809 & 34.39 & 65.61 & 27.247 & 51.981 & 42.5 & 81.0 \\
\hline Pakistan & 23.47 & 5.136 & 82.05 & 17.95 & 68.505 & 14.991 & 106.8 & 23.4 \\
\hline Thailand & 0 & 4.674 & 0.00 & 100.00 & 0.000 & 13.643 & 0.0 & 21.3 \\
\hline Vietnam & 0 & 0.777 & 0.00 & 100.00 & 0.000 & 2.268 & 0.0 & 3.5 \\
\hline TOTAL & 191.172 & 301.151 & & & 558 & 879 & 870 & 1,371 \\
\hline
\end{tabular}

\section{Reserve Growth}

Reserve growth (also known as field growth or appreciation), is a factor defined by the USGS as

15 the increase in reserves of a previously discovered field through time. It can provide a very significant

16 increase to gas reserves. Many commentators who are concerned about impending gas shortages do not

17 give consideration to reserve growth. However, in spite of its complexity, it is essential to account for

18 this factor when assessing the availability of gas. 
As classified by the USGS, reserve growth applies to 'known' volumes (cumulative production

2 plus remaining reserves). In this study, reserve growth also applies to endowment volumes. It is

3 estimated by calculating a percentage for reserve growth, based on 'known' volumes from [4], and

4 applying it to estimated gas endowment volumes of both assessed and unassessed Asia Pacific

5 provinces.

We have calculated reserve growth percentages using values from Table 6. In the 'world total'

7 section, for instance, we calculate the reserve growth percentage of known gas, which amounts to

$855.92 \%$. This comes from dividing reserve growth (3,660 TCFG) by the summation of cumulative

9 production plus remaining reserves $(1,752 \mathrm{TCFG}+4,793 \mathrm{TCFG})$.

10

11 Table 6

12 Calculation of Reserve Growth Percentages - based on data from [4].

13

\begin{tabular}{|c|c|}
\hline & $\begin{array}{c}\text { Natural Gas } \\
\text { (TCFG) }\end{array}$ \\
\hline \multicolumn{2}{|l|}{ World (excluding USA) } \\
\hline Undiscovered conventional & 4669 \\
\hline Reserve growth (conventional) & 3305 \\
\hline Remaining reserves & 4621 \\
\hline Cumulative production & 898 \\
\hline \multirow[t]{2}{*}{ Total } & 13493 \\
\hline & $\begin{array}{c}\text { Gas } \\
\text { (TCFG) }\end{array}$ \\
\hline \multicolumn{2}{|l|}{ USA } \\
\hline Undiscovered conventional & 527 \\
\hline Reserve growth (conventional) & 355 \\
\hline Remaining reserves & 172 \\
\hline Cumulative production & 854 \\
\hline \multirow[t]{2}{*}{ Total } & 1908 \\
\hline & $\begin{array}{c}\text { Gas } \\
\text { (TCFG) }\end{array}$ \\
\hline \multicolumn{2}{|l|}{ World Total } \\
\hline Undiscovered conventional & 5196 \\
\hline Reserve growth (conventional) & 3660 \\
\hline Remaining reserves & 4793 \\
\hline Cumulative production & 1752 \\
\hline Total & 15401 \\
\hline Known volumes & 6545 \\
\hline Reserve growth based on known volumes (\%) ${ }^{\text {a }}$ & 55.92 \\
\hline
\end{tabular}

a. Calculated as [Reserve Grow th / (Remaining Reserves + Cumulative Prod)] x 100 


\subsection{Discussion of Reserve Growth Application}

The calculated percentages of world reserve growth are used in the estimation of endowment

4 volumes plus reserve growth of both the previously assessed and unassessed Asia Pacific provinces. The

5 basic assumptions in the application are that (1) the reserve growth percentages based on known

6 volumes will be the same for endowment volumes, (2) the reserve growth percentage for the world is

7 applicable to the Asia Pacific region, and (3) the ranking of endowment volumes plus reserve growth, by

8 size, will be the same as the ranking of the endowment volumes without reserve growth.

9 The estimated VSD curve for gas endowment plus reserve growth (55.92\%), for 290 Asia Pacific

10 provinces, is presented in Figure 6. This figure is similar to Figure 5, with the only difference being the

11 addition of the 'plus reserve growth' curve. It lies to the right of the original curve showing the VSD

12 estimate of 290 provinces without reserve growth. It shows that at each province, each volume is now

$1355.92 \%$ greater than the original estimate. The calculated gas endowment volume for 290 provinces

14 including reserve growth is 2,240 TCFG.

Figure 7 is a bar graph showing the Asia Pacific natural gas endowment estimated by [4], the

16 VSD estimate for the previously unassessed provinces, and the calculated reserve growth for the region. 


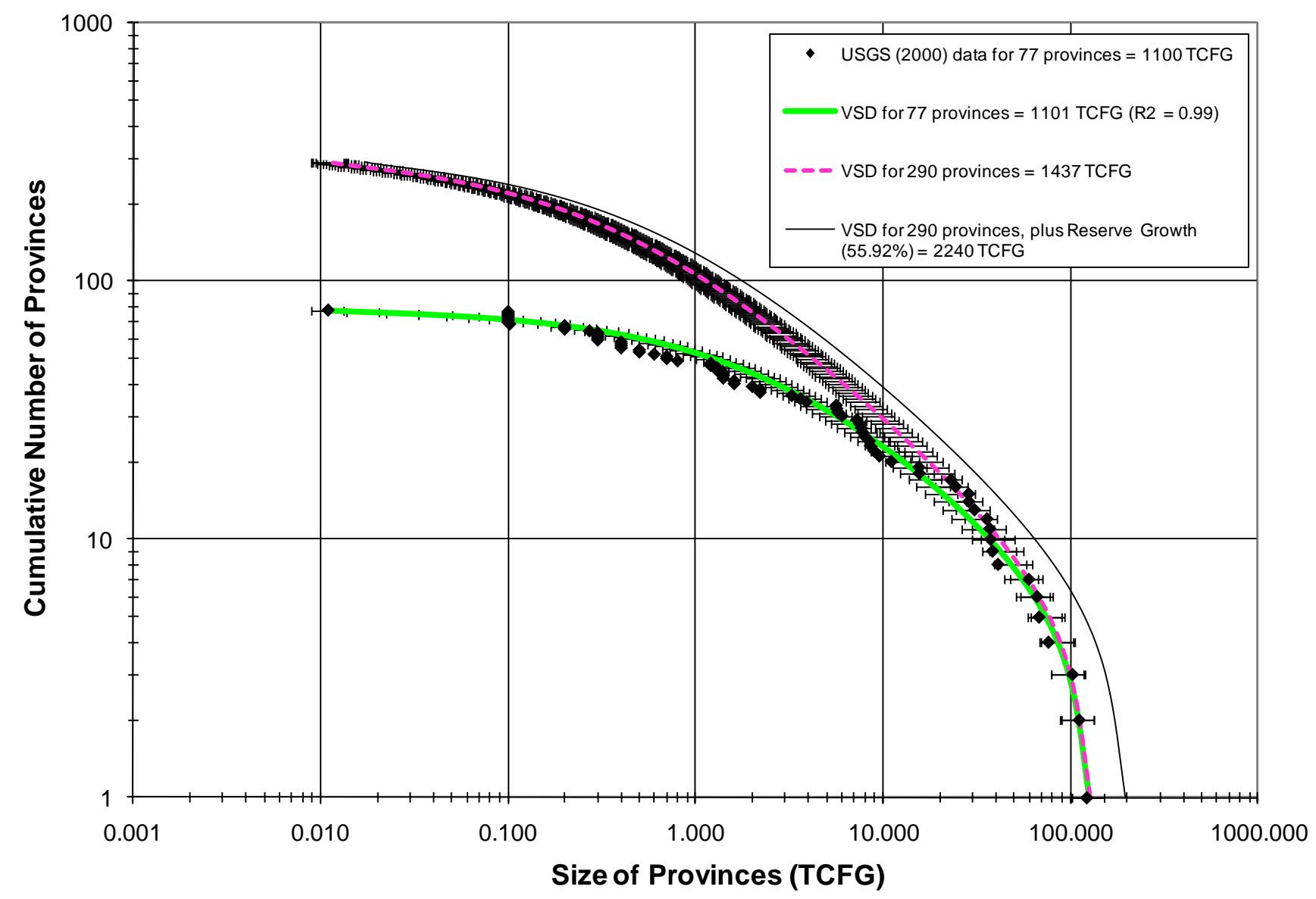

Fig. 6. VSD estimate for 290 Asia Pacific provinces (including unassessed provinces and reserve growth). 
TOTAL

2240 TCFG

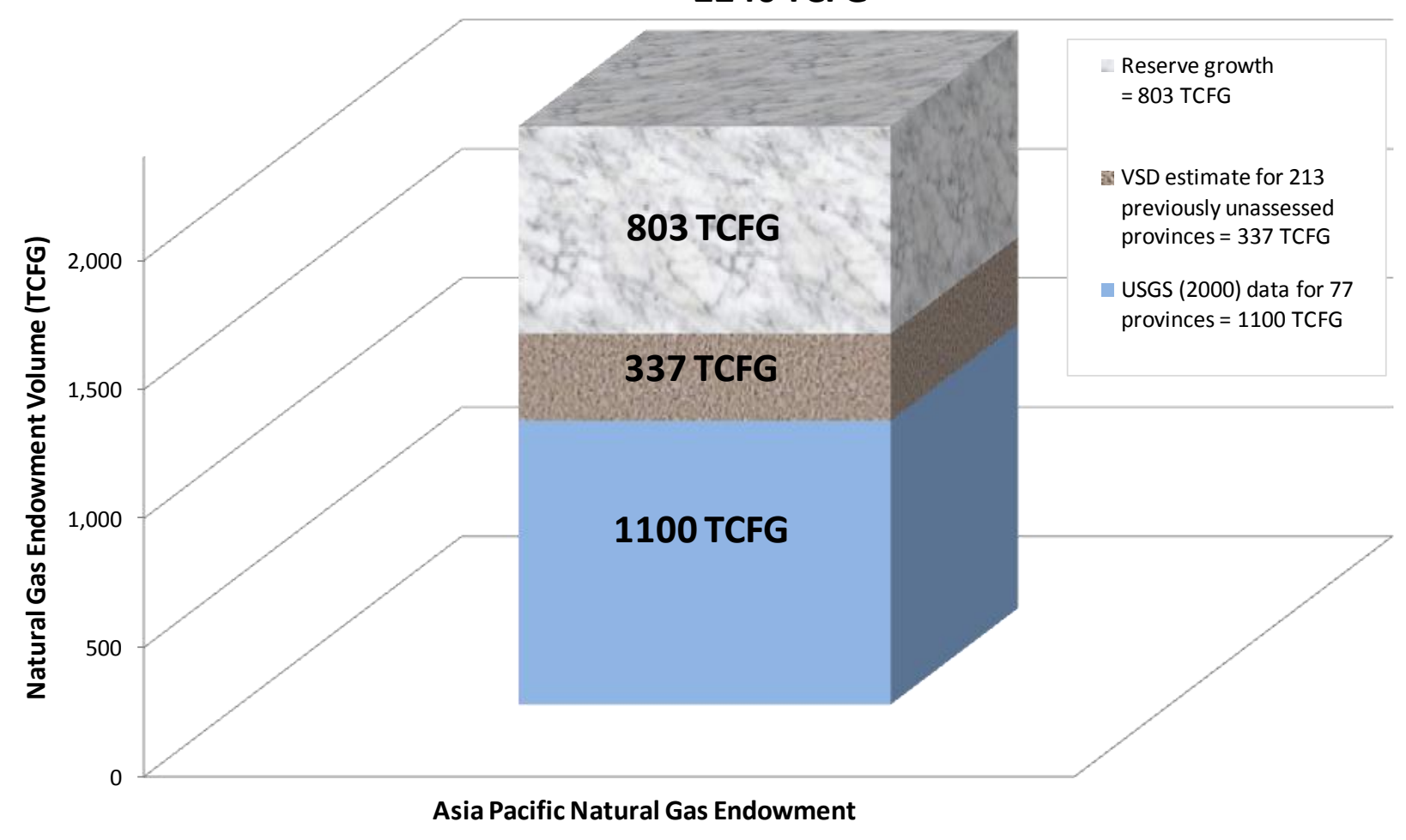

2 Fig. 7. Asia Pacific natural gas endowment divided into volumes from assessed provinces, unassessed 3

The rows under column 4 in Table 7 indicate how many years future gas volumes in Asia Pacific

7 would last assuming production grows in the future at $0 \%, 3 \%, 6 \%$, or $10 \%$ per year. ${ }^{5}$

\footnotetext{
5 'Future volumes' are equal to endowment volumes minus cumulative production. Thus, Asia Pacific cumulative production of 84 TCFG [4] is subtracted from the endowment volumes presented earlier, resulting in the following future volumes:
}

From [4]: 1,100 TCFG -84 TCFG $=1,016$ TCFG

Including Unasessed Provinces: 1,437 TCFG -84 TCFG = 1,353 TCFG

Including Unassessed Provinces and Future Reserve Growth: 2,240 TCFG -84 TCFG = 2,156 TCFG 
At current production rates, future volumes from previously assessed provinces assuming no

2 reserve growth would last for 69 years. Adding in future volumes from unassessed provinces increases

3 this figure to 91 years and considering reserve growth pushes it to 146 years.

$4 \quad$ Figure 8 shows the relationship between the life expectancy and the production growth rates of

5 Asia Pacific future gas volumes in graphical form. The lower curve represents volumes from previously

6 assessed provinces. The middle curve includes unassessed provinces, while the upper curve adds in

7 reserve growth. As can be seen, the years of life expectancy decrease exponentially as production

8 growth rates increase.

$9 \quad$ Table 7

10 Life Expectancies (Years).

11

\begin{tabular}{|c|c|c|c|c|c|c|c|}
\hline 1 & 2 & 3 & & & & & 5 \\
\hline \multirow{2}{*}{$\begin{array}{l}\text { Asia Pacific } \\
\text { Conventional } \\
\text { Gas }\end{array}$} & \multirow{2}{*}{$\begin{array}{l}\text { Future } \\
\text { Volumes } \\
\text { (CFG) }\end{array}$} & \multirow{2}{*}{$\begin{array}{c}2007-2009^{\mathrm{a}} \\
\text { Average Annual } \\
\text { Production (CFG) }\end{array}$} & \multicolumn{4}{|c|}{$\begin{array}{l}\text { Life Expectancy in Years, at Various } \\
\text { Growth Rates in Production }\end{array}$} & \multirow{2}{*}{$\begin{array}{c}\text { Average Annual } \\
\text { Growth in Production } \\
1979-2009(\%)\end{array}$} \\
\hline & & & $0 \%$ & $3 \%$ & $6 \%$ & $10 \%$ & \\
\hline From USGS (2000) & $1.016 \mathrm{E}+15$ & \multirow{3}{*}{$1.48 \mathrm{E}+13$} & 69 & 37 & 27 & 21 & \multirow{3}{*}{6.61} \\
\hline Including Unassessed Provinces & $1.353 E+15$ & & 91 & 44 & 31 & 23 & \\
\hline Including Unassessed Provinces and Reserve Growth & $2.156 \mathrm{E}+15$ & & 146 & 56 & 38 & 28 & \\
\hline
\end{tabular}

Notes:

a. Average annual production comes from [10]

b. Life expectancies estimated by this study

12

c. Average annual growth in production calculated from [10]

13

14

15

16 


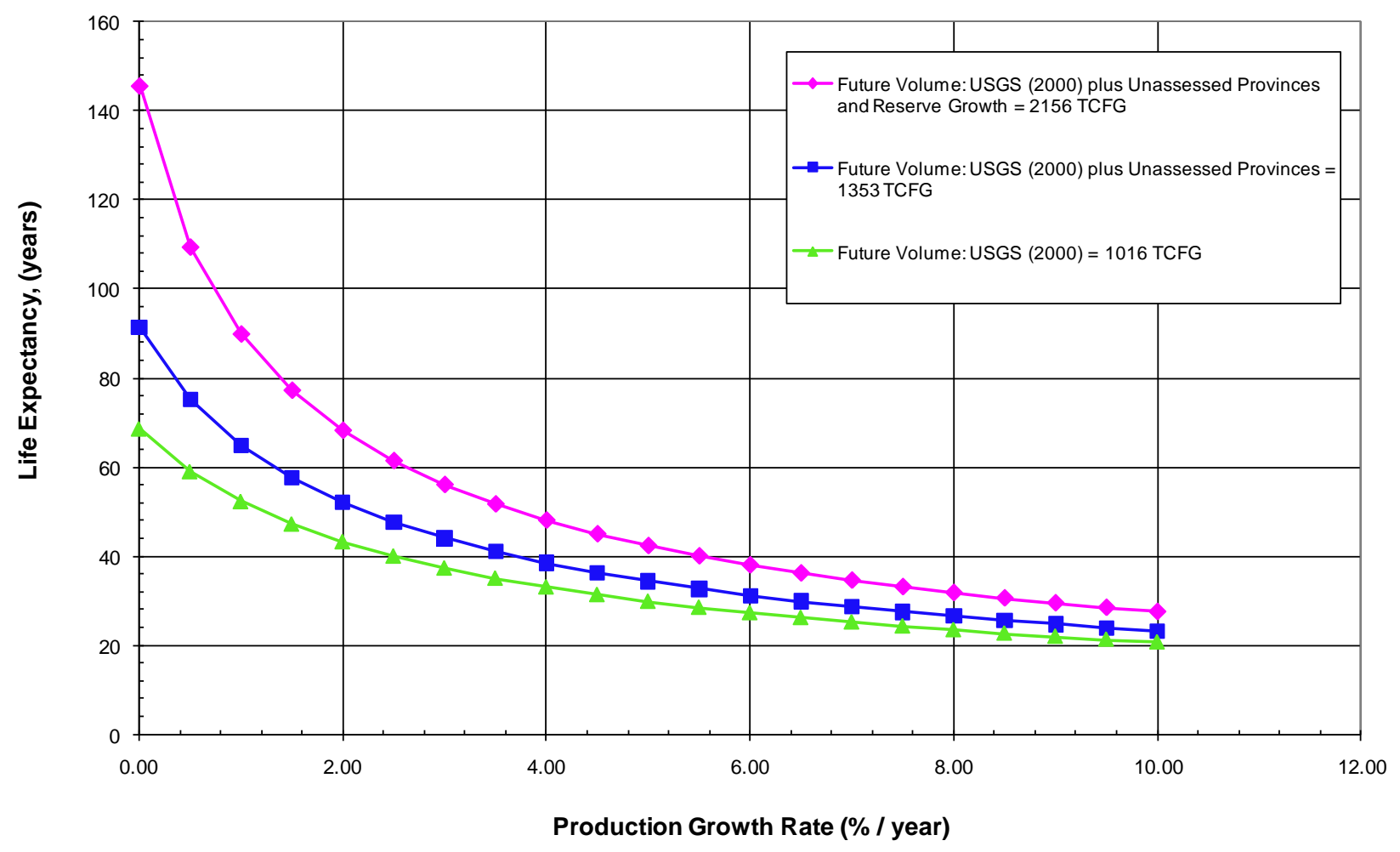

Fig. 8. Life Expectancies at Various Production Growth Rates

\section{Conclusions and Implications}

As energy use continues its upward trajectory in Asia Pacific, it will be important for

policymakers to increase the market share of natural gas in the energy mix. Thus, it is also imperative to generate reliable estimates of the total conventional natural gas endowment. Size distribution analysis is useful in this regards as it provides a simple and effective complement to more complex and time-

11 consuming geological methods.

12 This paper uses a Variable Shape Distribution (VSD) model to estimate the total gas endowment 13 in previously assessed and unassessed Asia Pacific provinces. Historically, all methods used to

14 determine the relation between the size and number of gas provinces were based on an assumed form of 
1 the size distribution (e.g. Pareto [fractal], or lognormal). The VSD model is unique in that it allows

2 actual gas resource data to determine the relationship.

4 for 77 Asia Pacific provinces out of a total of 290, so there are 213 provinces left unassessed. Given the

5 validations of the VSD demonstrated in this paper, the model can be used to estimate reasonable

6 endowment volumes of all 290 provinces.

7 Results of the VSD model indicate that there is a total of 1,437 TCFG in those 290 provinces. If

8 reserve growth is accounted for, the gas endowment volume increases to 2,240 TCFG. It is estimated

9 that Australia, Indonesia, and China together account for over $60 \%$ of this total endowment. In addition,

10 over $60 \%$ of the Asia Pacific endowment is projected to be in offshore areas.

11 Thus, the quantity of available conventional gas in the Asia Pacific region is greater than often

12 assumed, since there is a tendency to overlook unassessed provinces and reserve growth. An important

13 implication is that natural gas is likely to last longer than some commentators claim. At current

14 production rates, the volumes in previously assessed and unassessed provinces, including the effects of

15 reserve growth, would last 146 years. If production grows at $3 \%$ per year, the life expectancy decreases

16 to 56 years.

17 This abundance of natural gas in Asia Pacific should help satisfy energy demand as rapid

18 economic growth continues. Furthermore, an increase of natural gas in the energy mix has the potential

19 to lead towards a low carbon economy.

In spite of the benefits associated with a large conventional and unconventional gas endowment

21 in Asia Pacific, there is some concern by major liquefied natural gas (LNG) exporters about a decrease

22 in LNG demand. This would happen because rapidly developing countries like China and India, with

23 their considerable domestic natural gas resources, would no longer demand large quantities of LNG. 
1 However, given the sheer size of gas demand in these growing economies, the LNG market is unlikely

2 to diminish in the foreseeable future. Furthermore, if gas can capture some of the huge market share

3 currently occupied by coal, then China and India will require tremendous gas supply from domestic and

4 foreign sources, conventional or unconventional.

5 To benefit from increased use of natural gas, public policy must facilitate the development of

6 transparent and functional gas markets in Asia Pacific. Appropriate regulatory, legal, and fiscal

7 conditions should exist in both producing and consuming countries in order to reduce the risk associated

8 with investment, transportation, infrastructure, and carbon constraints.

11 APPENDIX A: MATHEMATICAL DEVELOPMENT OF THE VSD MODEL

12 A.1 Fractal and Pareto Distributions

A fractal distribution is provided by a power law of the form [11, 12]:

15 where:

$16 D$ - constant fractal dimension.

$17 \quad C$ - constant of proportionality.

$18 r$ - some quantity (e.g. natural gas volume in TCFG).

$19 N(r)$ - number of objects with a quantity equal to or greater than $r$.

20 For conventional oil and gas volumes (V),

$$
V=r^{3}
$$

22 and consequently, Equation A.1 becomes:

$$
N(V)=C V^{-D / 3}
$$


where:

$2 N(V)$ - distribution function of $V$.

4 given by:

$$
n(V)=\frac{d N(V)}{d V}
$$

7 by:

$$
N(V)=\int_{V \min }^{V \max } n(V) d V
$$

9 where $V_{\min }$ and $V_{\max }$ are the minimum and maximum volumes, respectively.

10 The distribution function, Equation A.3, can be written as a Pareto power law, or Pareto

11 distribution, as follows [12]:

$$
N(V)=C V^{-a_{p}}
$$

13 where $a_{p}$ is a shape parameter (also known as shape exponent, Pareto exponent, Pareto constant, or

14 fractal dimension). Note that based on the above development, the shape parameter $\left(a_{p}\right)$ is equal to 3

15 times the fractal dimension $(D)$.

Taking logarithms of both sides of Equation A.6 leads to:

$$
\log N(V)=\log (C)-a_{p} \log V
$$

19 slope equal to $-a_{p}$ and an intercept, at $V=1$, equal to $C$. 


\section{$1 \quad$ A.2 Variable Shape Distribution (VSD) Model}

As mentioned earlier, development of the VSD starts by observing the curvature given by the data points from [4] on the log-log plot. We then create the VSD model which allows the data to

4 determine the specified relationship between the size and number of provinces. Following the work of Pareto and [11, 12], the VSD is given by:

$$
N_{t}=\frac{1}{r_{t}^{a_{t}}}
$$

7 where:

$8 a_{t}$ - unknown, variable shape exponent.

$9 \quad N_{t}$ - cumulative number of provinces, bound by [4].

$10 r_{t}$ - estimated normalized volume of a province.

11 Thus, the VSD equation is somewhat similar to Pareto's equation. ${ }^{6}$ The significant difference is 12 that the shape exponent in Pareto's equation is a constant, while the shape exponent in the VSD model

13 can vary. When the shape exponent in the VSD model is constant, the VSD equation is a Pareto

14 equation. By using normalized volumes, the constant of proportionality, $C$, is equal to 1 . Since there are

15 two unknowns in Equation A.8, $a_{t}$ and $r_{t}$, an auxiliary equation has been developed for calculating the

16 two unknowns. The equation has the form:

$$
N_{t}=\frac{1}{r_{t}^{a_{t}}}=\frac{1}{r_{v}^{a_{p}}+r_{m}^{a_{m}}}
$$

where:

\footnotetext{
${ }^{6}$ Other extensions of the Pareto distribution include the Parabolic Fractal Distribution [13] and the Log-Pareto Distribution [14]. These extensions, like the Pareto and lognormal distributions, are based on assumed forms of the size distribution of oil and gas accumulations.
} 
$1 \quad a_{m}$-slope of line between (1) point of maximum number of provinces $\left(N_{x}\right)$ and minimum USGS

2 province volume $\left(V_{m}\right)$ and (2) point of minimum number of provinces $\left(N_{m}=1\right)$ and maximum volume

$3\left(V_{x}\right)$ given by Pareto straight line at $N_{m}=1$ (see Figure A.1). ${ }^{7}$

$4 a_{p}$-slope of straight line approximated from USGS data points; same as slope of Pareto distribution (see

5 Figure A.1).

$6 r_{m}$ - normalized, minimum USGS province volume $\left(r_{m}=V_{m} / V_{x}\right.$, where $V_{m}$ is the minimum USGS

7 province volume, and $V_{x}$ is the maximum volume given by the Pareto straight line at a number of

8 provinces equal to 1$)$.

$9 \quad r_{v}$ - estimated normalized volume of a province minus the normalized minimum USGS volume.

10 The right hand side of Equation A.9 has been empirically estimated and tested against the data

11 published in [4], providing reasonable results. Since the number of provinces $\left(N_{t}\right)$ and the normalized,

12 minimum USGS province volume $\left(r_{m}\right)$ are known from [4], and the slopes $a_{p}$ and $a_{m}$ can be determined

13 from the graphed data, it is possible to re-arrange Equation A.9 to determine $r_{v}$, as follows:

$$
r_{v}=\left(\frac{1}{N_{t}}-r_{m}^{a_{m}}\right)^{\frac{1}{a_{p}}}
$$

$$
r_{t}=r_{v}+r_{m}
$$

${ }^{7}$ In equation form, this slope is given by $a_{m}=\frac{\log N_{x}-\log N_{m}}{\log V_{x}-\log V_{m}}$ 
Then, to 'de-normalize' $r_{t}$, and get the estimated volume of a province, the following equation is

4 where:

$5 V_{t}$ - estimated volume of a province before right-tail adjustment.

$6 \quad V_{x}$ - maximum volume given by Pareto straight line at number of provinces $=1$.

used:

$$
V_{t}=r_{t} V_{x}
$$
arrange Equation A.9 to solve for the variable shape exponent $\left(a_{t}\right)$, as follows:

$$
a_{t}=\frac{\log \left[r_{v}^{a_{p}}+r_{m}^{a_{m}}\right]}{\log r_{t}}
$$

where:

$a_{t}$ - variable shape exponent; slope of line between point of any estimated volume and the maximum volume point given by the Pareto straight line at number of provinces equal to 1 (see Figure A.2).

\section{A.3 Adjusting Right Tail (Largest Volumes) of VSD} straight line. Often, more than one of the larger volumes will not lie on the line. ${ }^{8}$

To get a more accurate, estimated curve that fits over the largest volumes, an exponential bending the estimated curve in the direction of the actual USGS data. The exponential function is as follows:

After calculating $r_{v}$ and $r_{t}$ using Equations A.10 and A.11, respectively, it is possible to re-

Notice that in Figure A.2, the data point for the largest province, $V_{L}$, does not lie on the Pareto function has been incorporated empirically into the VSD model. The function has the effect of smoothly

\footnotetext{
${ }^{8}$ This is a common occurrence in Pareto distributions. It has been interpreted by [12] to be the result of sub-populations, each of which have the same Pareto shape exponent (slope), but different largest volumes.
} 
where:

$2 S$ - severity exponent that is determined by trial and error. It controls the extent to which the estimated

3 VSD curve will separate from the Pareto straight line (on the right tail of the distribution, near the

4 largest volumes).

$5 \quad V_{s}$ - parameter that corresponds approximately to the point at which the largest USGS provinces begin to

6 deviate from the Pareto straight line, on the right tail of the distribution, near the largest volumes (see

7 Figure A.2).

$8 V_{t}$ - estimated volume of a province before right-tail adjustment.

9 Another parameter incorporated into the VSD model to get a more accurate fit of the largest

10 USGS volumes is approximated by:

$$
\psi=\frac{V_{L}}{V_{X}}
$$

12 where:

$13 \psi$ - separation ratio that controls the amount of separation between the Pareto straight line and the

14 estimated VSD curve (on the right tail of the distribution, near the largest volumes).

$15 V_{L}$ - volume of the largest USGS province.

$16 V_{x}$ - maximum volume given by Pareto straight line.

17 Three parameters $\left(V_{s}, \psi\right.$, and $\left.\mathrm{S}\right)$ only affect the right tail of the VSD curve, near the largest

18 volumes. They are incorporated so that the VSD curve will fit over the largest volumes that do not lie on 19 the Pareto straight line.

20 The exponential function (see Equation A.14) and the separation ratio $(\psi)$ are used to improve

21 the estimate of a province's volume as follows:

$$
\hat{V}_{i}=\frac{V_{t} \cdot \psi}{\psi+(1-\psi) \cdot f\left(V_{t}, V_{s}\right)}
$$


1 where:

$2 \quad \hat{V}_{i}$ - estimated volume of a province.

3 Expanding the exponential function, $f\left(V_{t}, V_{s}\right)$, in Equation A.16 gives:

$$
\hat{V}_{i}=\frac{V_{t} \cdot \psi}{\psi+(1-\psi) \cdot\left(1-\exp \left(-V_{t} / V_{s}\right)\right)^{S}}
$$

5 where, as shown earlier in Equation A.12:

6

10 giving:

$$
V_{t}=r_{t} V_{x}=\left[\left(\frac{1}{N_{t}}-r_{m}^{a_{m}}\right)^{\frac{1}{a_{p}}}+r_{m}\right] \cdot V_{x}
$$

Further expansion of Equation A.18 results in:

$$
V_{t}=\left[\left(\frac{1}{N_{t}}-\left(\frac{V_{m}}{V_{x}}\right)^{\left(\frac{\log N_{x}-\log N_{m}}{\log V_{x}-\log V_{m}}\right)}\right)^{\frac{1}{a_{p}}}+\frac{V_{m}}{V_{x}}\right] \cdot V_{x}
$$

When $V_{t}$, from Equation A.19, is substituted into Equation A.17, all the terms are expanded,

11

$$
\hat{V}_{i}=\frac{\left\{\left[\left(\frac{1}{N_{t}}-\left(\frac{V_{m}}{V_{x}}\right)^{\left(\frac{\log N_{x}-\log N_{m}}{\log V_{x}-\log V_{m}}\right)}\right)^{\frac{1}{a_{p}}}+\frac{V_{m}}{V_{x}}\right] \cdot V_{x}\right\} \cdot(\psi)}{(\psi)+[1-(\psi)] \cdot\left[1-\exp \left(-\left\{\left[\left(\frac{1}{N_{t}}-\left(\frac{V_{m}}{V_{x}}\right)^{\left(\frac{\log N_{x}-\log N_{m}}{\log V_{x}-\log V_{m}}\right)}\right)^{\frac{1}{a_{p}}}+\frac{V_{m}}{V_{x}}\right] \cdot V_{x}\right\} \cdot V_{s}^{-1}\right]\right]^{S}}
$$

Equation A.20 is used to generate, via non-linear regression, the estimated VSD curve shown in

13 Figure A.2. The validity of the equation can be confirmed by visual inspection of Figure A.2. Further

14 confirmation is provided by the coefficients of determination (nearly always 0.98 or 0.99 ) and the 
1 volume estimates presented earlier that compare very well with the actual volumes published by the 2 USGS (2000) study.

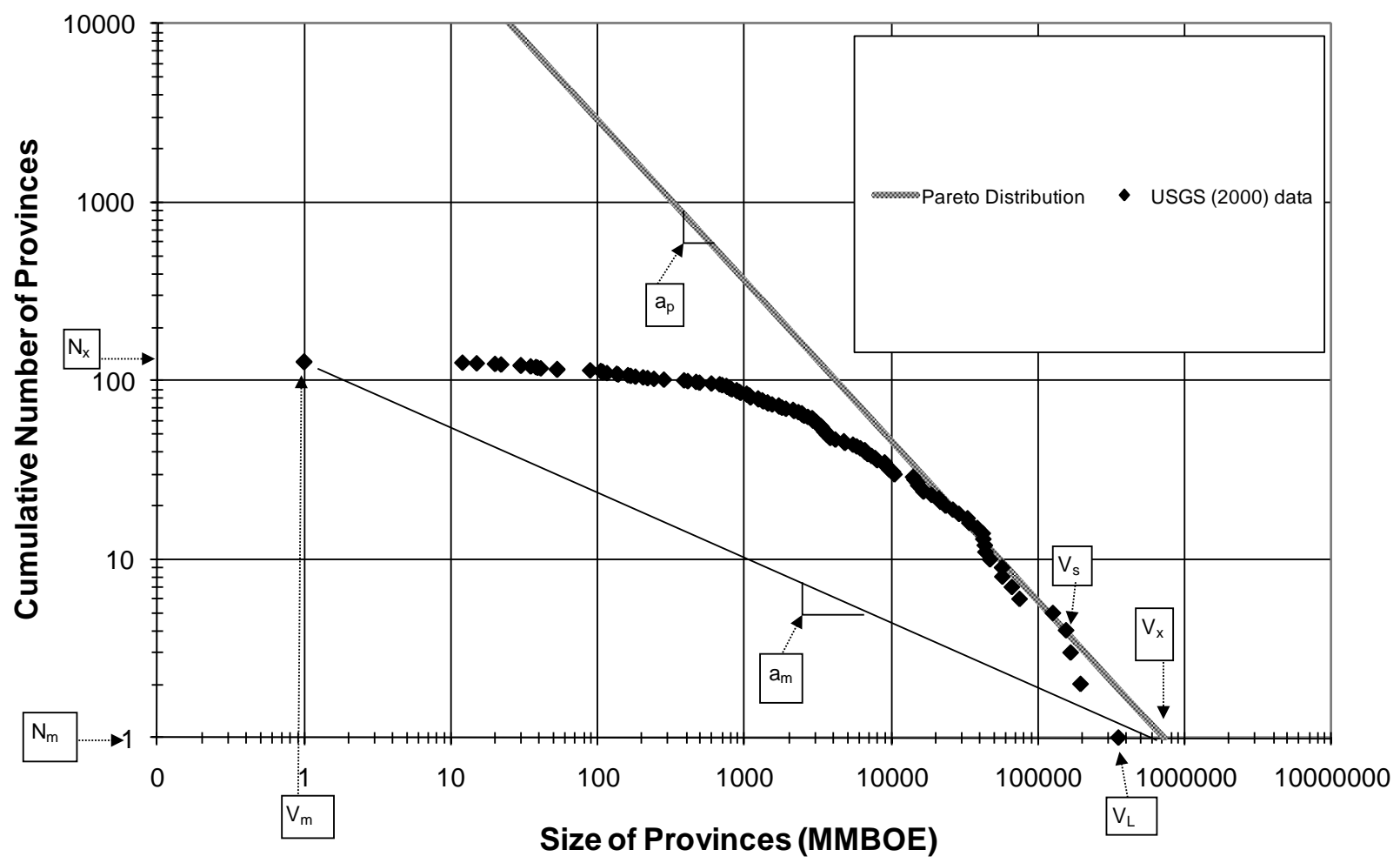

Fig. A.1. Schematic showing VSD model terminology. 


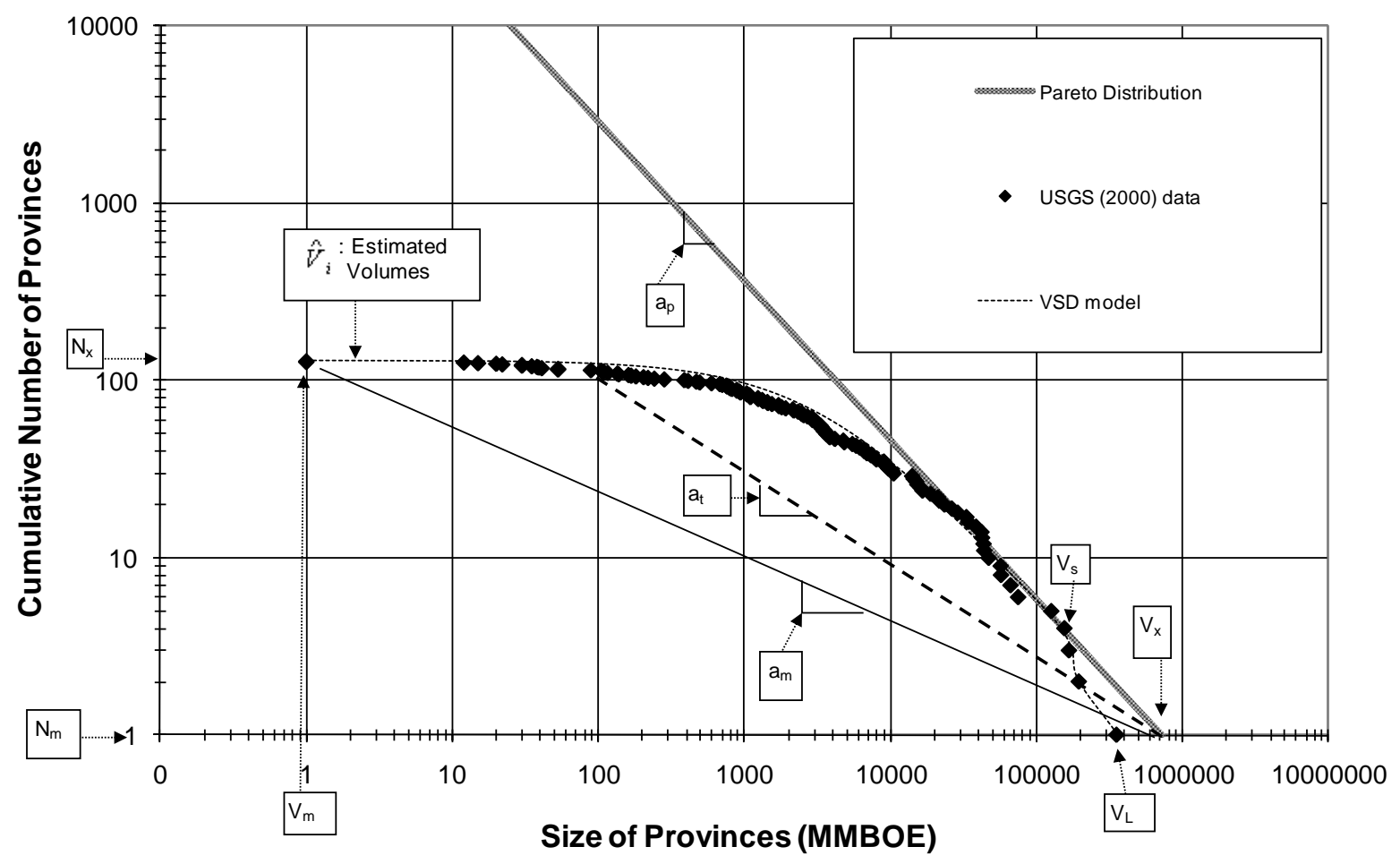

Fig. A.2. Schematic showing additional VSD model terminology.

\section{References}

8 [1] International Energy Agency. World Energy Outlook. Paris, France: Organization for Economic Cooperation and Development; 2010.

[2] Aguilera RF, Harding T, Krause F, Aguilera R. Natural Gas Production from Tight Formations: A Global Perspective. Presented as a paper at the $19^{\text {th }}$ World Petroleum Congress in Madrid, Spain, June 13 29-July 3, 2008.

[3] Aguilera RF, Eggert RG, Lagos G., and Tilton JE. Depletion and the Future Availability of

[4] United States Geological Survey. World Petroleum Assessment. CD-ROM; 2000.

[5] Aguilera RF. Assessing the Long Run Availability of Global Fossil Energy Resources. PhD Dissertation. Colorado School of Mines; 2006. 
[6] Adelman MA, Houghton JC, Kaufman GM, Zimmerman MB. Energy Resources in an Uncertain Future: Coal, Gas, Oil, and Uranium Supply Forecasting. Cambridge, MA: Ballinger Publishing Company; 1983.

[7] Barton CC. A New Approach to Estimating Hydrocarbon Resources. United States Geological Survey Fact Sheet; 1995.

http://energy.usgs.gov/factsheets/HydroRes/estimat.html (accessed 24 January 2011).

[8] Kaufman GM. Where have we been? Where are we going? Natural Resources Research 2005; 14 (3): 145-152.

[9] Drew LJ. Undiscovered Petroleum and Mineral Resources, Assessment and Controversy. New York and London: Plenum Press; 1997.

[10] British Petroleum. Statistical Review of World Energy 2010. London; 2010.

[11] Mandelbrot BB. The Fractal Geometry of Nature. San Francisco, CA: Freeman; 1982.

[12] Barton CC, Scholz CH. The Fractal Size and Spatial Distribution of Hydrocarbon Accumulations. In: Barton CC, LaPointe PR, editors. Fractals in Petroleum Geology and Earth Processes. New York: Plenum Press;1995.

[13] Bettini C. Forecasting Populations of Undiscovered Oil Fields with the Log-Pareto Distribution. PhD Dissertation. Stanford University; 1987.

[14] Laherrere JH. Parabolic Fractal Distributions in Nature. CR Academy of Sciences 1996; 322 (7): $535-541$. 